\title{
O INDÓMITO NÚMERO pi (conto matemático)
}

\author{
LABRANHA ANTOM
}

IES San Clemente

\section{Enigmática sedución}

Circunferencia viu pasar un soberbio sombreiro de copa envolto nunha bandeira multicolor. Despótico e altivo, exhibía presuntuoso seu imperial poderío a ombros dun esforzado xornaleiro que agochaba a súa humilde condición baixo un raído suadoiro. Ansiosa, deu un chimpo onda o sombreiro e díxolle:

_Se non é moito preguntar, vostede que raio ten?

_Eu? -respondeulle fachendoso- 0 da cabeza deste coitado

que me carrexa polo mundo.

Entón Circunferencia faloulle ao obreiro:

_Que raio ten a súa cabeza?

O malpocado respondeu:

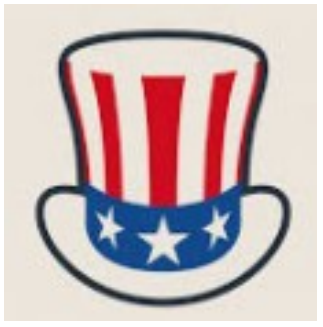

_0 que Don Sombreiro precise para asentar.

Padecía ela dun atávico desasosego, herdado de tempos bíblicos, de cando a construcióndo Templo de Salomón. Seducido por Circunferencia, o rei dos xudeus ordenou fundir un disco de prata de 5 cotobelos de raio. Entrenzando brillantes fíos de ouro, compuxo persoalmente un abraiante cordel de 31'4 cotobelos de longo, para orlaren o disco. Porén, o dourado adival non alcanzou e aí lle quedou a Circunferencia un minúsculo buraquiño, unha eiva que continúa aflixíndoa. 


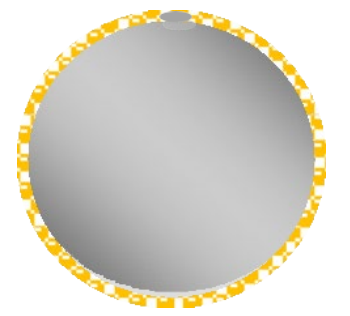

Talvez as circunferencias sexan os obxectos matemáticos máis sedutores de cantos haxa, quizais por seren primordialmente democráticas: Idénticas en todos os puntos; todos eles equidistando dun centro imaxinario por medio do cal a colectividade conserva o equilibrio.

Todos os puntos individuo sábense así iguais, sen xerarquías, sen privilexios

Só o raio as singulariza, porque establece un tamaño, unha prelación entre elas, facendo a unhas grandes mentres outras fican pequenas. Porén, as circunferencias conservan a simetría de seu natural e recoñécense homoxéneas na súa esencia. Non como lles acontece ás comunidades humanas, que dexeneran en relaciónsde dominio e clases sociais, mesmo en miserias.

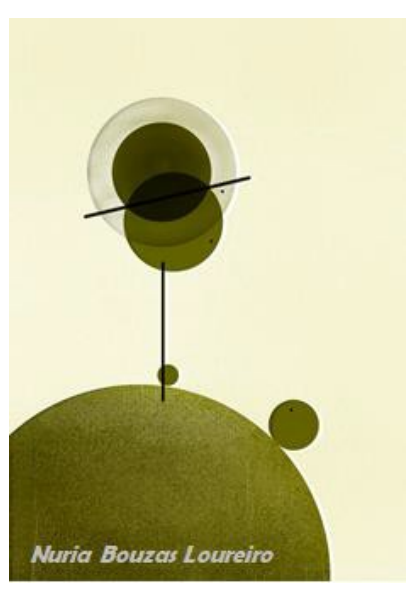

\section{Cotobelos}

0 termo "cotobelo" refire unha antiga medida antropomórfica: distancia media entre ocóbado e a punta do dedo central dun individuo adulto -collida daquela maneira-. Como adoitaba suceder nas unidades de medida populares, había variacións dun lugar a outro. 0 coñecido como "cotobelo de ribeira", por exemplo, equivalía a uns 57'4 cm. Os cotobelos (cóbado sagrado) nos que se expresaban as medidas do templo de Salomón (S. X a.n.e.), equivalerían a uns $54 \mathrm{~cm}$-iso segue actualmente discutíndose (mesmo o propio Newton tíñase interesado pola cuestión)-.

Aínda conscientes de que non tería podido ser así, asignémoslle a $\pi$ o valor, escolar por excelencia, de 3’14, cunha intencionalidade pedagóxica: manter provisionalmente a validez do coñecemento adquirido/admitido a respecto diso, para non interferir na proposta matemática: aproximación, erro e acoutamento.

Un dos versículos bíblicos do II Libro das Crónicas, referíndose á construción do Templo de Salomón, describe un disco de metal fundido "que tiña dez cotobelos dunha beira á outra, totalmente redondo, a súa altura era de cinco cotobelos e un cordón de trinta cotobelos de longo cinguíao ao redor". Outra descrición semellante aparece, tamén na Biblia, no I Libro dos Reis.

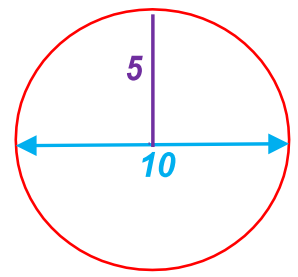


Interpretamos esa pasaxe mediante a figura que se lle adxunta. Nese caso, mesmo se non fosen conscientes, os fundidores estarían utilizando para $\pi$ o valor de 3 ; aproximado, aíndaque non moi axustado para a época (erro da orde de décimas), polo que se sospeita que aos redactores ou tradutores non lles debeu parecer significativo informar con maior precisión:

Practicamente un milenio antes, no papiro Rhind -Exipto-, manéxase o valor de 256/81, que en notación decimal sería 3’16049... E tamén, uns setecentos ou seiscentos anos antes, na Mesopotamia utilizábanse valores coma 3+1/8, que sería 3’125, e incluso mellores, coma 3+1/7, que vén sendo 3’14285... (erros da orde de centésimas, os primeiros, e milésimas este último).

\section{Enredando na aula}

0 relato vén a conto de tentar contribuír -como se indica no Currículo a respecto da interrelación entre as diferentes áreas de coñecemento-, neste caso dende a competencia matemática, á competencia lingüística. Con el preténdese, finalmente, incitar a botar as contas e indagar/enredar sobre a circunferencia de Salomón e se lle quedaba ou non o tal buraquiño e, se lle quedase, de canto era.

Traballar con "cotobelos" non é inmediato: o descoñecemento do termo parece constituír un obstáculo cognitivo, malia termos feito antes frecuentes cálculos de áreas de figuras básicas só con números indicados sobre os debuxos, sen concretar que unidade se empregaba, acorridos pola típica formulación: u.s. (unidades de superficie).

Será, talvez, oportuno comentar o que se menciona no primeiro parágrafo do epígrafe "Cotobelos" e propoñer calcular en cotobelos (sexan o que foren) e a seguir transformalos considerando que equivalen a $54 \mathrm{~cm}$ cada un. Así e todo, non resulta tan doado, mesmo habendo nesta ocasión unha unidade concreta... pero allea á experiencia escolar (e tamén á non escolar, naturalmente): un esforzo de abstracción segue a ser necesario.

Tampouco é inmediato, mesmo afeitos como estamos a botar as contas coa calculadora científica común, empregar o $\pi$ da calculadora. Hai teima co 3’14, o que, xa que o relato esta "trucado" para que isto aconteza, confirmaría a previsión do rei xudeu.

Preguntémonos, daquela, se non temos utilizado nunca outro valor para $\pi$. Quizais lembremos, entón, o 3’1416. Calculemos con ese valor, que semella indicar maior exactitude (xa que vén con máis decimais):

Serían, entón, 31'416 cotobelos de circunferencia, mentres que Salomón calculara 31'4, o que implicaría un erro de 0'016 cotobelos que, facendo o cambio de unidades, equivale a 0’864 cm. En case $1 \mathrm{~cm}$ se tería trabucado o sabio por ter utilizado unha cómoda pero insuficiente aproximación.

Este último detalle "en case $1 \mathrm{~cm}$ ", de darmos significación aos resultados cando houber un contexto propicio, non é ningunha trivialidade didáctica (é difícil imaxinar o que ocupa iso de 0'864 cm).

E xa postos, porque non empregar o valor de $\pi$ que nos ofrece a nosa calculadora? Agora o erro móstrase un chisquiño inferior: 0'860cm, e convén que pensemos no porqué:

Malia ter empregado máis cifras para representalo, 3’141592654, este número é máis pequeno ca 3’1416, xa que ambos os dous coinciden nas unidades, décimas, centésimas e milésimas, pero no 3’1416 hai 6 dezmilésimas, mentres que no 3’141592654 só hai 5 (case 6, realmente, pero 
non chega de todo a habelas; esta discusión tamén resulta moi sutil: un severo exercicio de aritmética decimal).

Por outra banda, a secuencia a seguir coa calculadora é, de por si, un exercicio algorítmico moi interesante:

0 que máis teño observado é: 2 x SHIFT $\pi$ x $5=-31.4$ = x $54=$, que demanda resultado con inmediatez, aínda sendo posibles outros que poden ser interesantes promovermos, coma:

$2 \times$ SHIFT $\pi \times 5-31.4=\times 54=$ ou $\quad(2 \times$ SHIFT $\pi \times 5-31.4) \times 54=$

Certo que isto pode cambiar segundo o modelo de calculadora empregado, pero en calquera caso sitúanos fronte a outro contido matemático: a xerarquía das operacións que, en definitiva, é un código de comunicación.

Sobre as posibilidades de o propio alumnado obter na aula un valor experimental para $\pi$, xa 0 comentei hai unha chea de anos, no no 47 do Boletín das Ciencias (outubro 2001), xunto coas deducións das fórmulas da lonxitude da circunferencia e da área do círculo.

\section{Arquímedes: Unha indagación xeométrica}

Expoñemos a continuación o método proposto por Arquímedes (Grecia, S. III a.n.e). Aínda que naquela altura a notación era moi enleada e calculaban con fraccións, imos velo dunha maneira máis lixeira, cuase escolar, experimentado - non sen suor- en $4^{\mathrm{o}}$ da ESO. Creo pertinente visualizar e declarar a priori a estratexia: cantos máis lados teña un polígono regular máis se aproxima na súa feitura ao círculo.

Xa Euclides, nos Elementos, tiña probado que en todas as circunferencias, grandes ou pequenas, a razón entre a lonxitude destas e o seu diámetro $(L / d)$ ten sempre o mesmo valor ${ }^{1}$. Arquímedes intentou crear un método formal para deducir o dito valor:

i) Se e dividísemos o hexágono regular en 6 triángulos iguais, estes serían equiláteros pois o ángulo central de $360^{\circ}$ quedaría divididoen ángulos de $60^{\circ}$, polo que os outros dous ángulos de cada triángulo sumarían $120^{\circ}\left(180^{\circ}-60^{\circ}\right)$ e, sendo iguais, serían tamén de $60^{\circ}$ cada un. Logo os triángulos son equiláteros, polo que os lados coinciden: entón o lado do hexágono é igual ao raio.

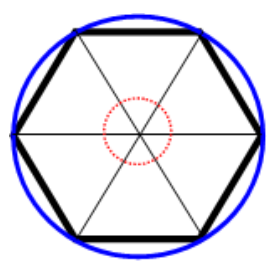

ii) Se inscribise nun círculo un hexágono regular o seu lado coincidiría co raio e se utilizase o perímetro do hexágono como unha medida aproximada da lonxitude da circunferencia tería:

$$
L \approx 6 r \stackrel{L=2 \pi r}{\longrightarrow} \pi \approx L / d=L / 2 r \approx 6 r / 2 r=3
$$

\footnotetext{
${ }^{1}$ No Boletín recreábase a proba de Euclides.
} 
iii) Dividindo cada lado en dous, imos construíndo sucesivamente polígonos regulares de máis lados: dodecágono, vintacatroágono...

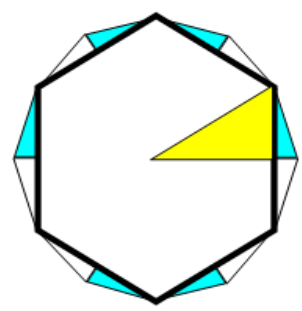

Sobre cada lado formaría dous triángulos rectángulos, aos que lle podería aplicar o teorema de Pitágonas. Tomemos o raio como unidade ${ }^{2}$ e ampliemos o esquema:

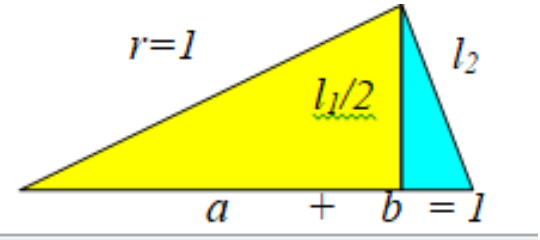

$$
\begin{aligned}
& l^{2}=\left(l_{1} / 2\right)^{2}+a^{2} \\
& l_{2}^{2}=\left(l_{1} / 2\right)^{2}+b^{2}
\end{aligned}
$$

Da primeira ecuación obtemos $a$, e como $b=l-a$, da segunda obteriamos o novo lado a partir do lado do polígono precedente.

Xa para o dodecágono obtemos un lado de 0,5176... o que, tomando o seu perímetro como aproximación da circunferencia proporciona unha lonxitude de 12 x 0,5176... $6,2116 \ldots$ se sendo $L=2 \pi r=2 \pi l$ polo que $\pi=L / 2 \approx 3,1058 \ldots$

Arquímedes construía tamén a serie equivalente de polígonos circunscritos, o que lle daba valores por exceso e, coma os anteriores eran por defecto, encaixaba o valor de pi.Laborioso, chegou a: 3'140845 < $<$ 3'142857.

Na linguaxe actual dicimos que 3’140845 é unha cota inferior e 3’142857 unha cotasuperior. Podemos, aínda, compensar o exceso co defecto facendo a media: 3’141851.

O proceso seguido coñécese como método de exhaución (acoutamento) e nel estaban contidos os alicerces do Cálculo Diferencial e Integral que se iría desenvolver uns dous mil anos despois.

\section{Leibniz: unha indagación analítica}

Teriamos que situarnos agora en $2^{\circ}$ de bacharelato -con maior suor aínda-. Leibniz (Alemaña, S.XVII/XVIII) foi, xunto con Newton -pero independentemente del-, un dos grandes creadores do

\footnotetext{
${ }^{2}$ A unidade de medida é un convenio. Unha colectividade ponse de acordo en cal lonxitude vai usar como referencia, ou que peso, ou que tempo... No 1791 a comunidade científica internacional acordou utilizar o metro,equivalente á dez millonésima parte do cuadrante do meridiano terrestre. Construíuse un metro patrón en platinoe iridio, que se conserva no Museo de Pesas e Medidas de París. Houbo varias mudanzas no intento de gañar precisión. Actualmente defínese como a distancia percorrida no baleiro pola luz en $1 / 299.792 .458$ segundos.
} 
Cálculo Diferencial e Integral. Entre outras, é moi coñecida a súa serie moi fácil de recordar ${ }^{3}$ :

$$
1-1 / 3+1 / 5-1 / 7+1 / 9 \ldots=\pi / 4
$$

Ao concluír que $1 /\left(1+\mathrm{x}^{2}\right)$ era a derivada de $\arctan x$ : a función definida como o arco de circunferencia $y$ (ou ángulo) que ten por tanxente o valor $x$, explorou a posibilidade de facer corresponder a dita derivada cunha progresión xeométrica (recordemos: $S_{\infty}=a_{1} /(1-r)$. Nese caso a sería 1, a razón debería ser $-\mathrm{x}^{2} \mathrm{e}$, daquela, a serie: $1-\mathrm{x}^{2}+\mathrm{x}^{4}-\mathrm{x}^{6}+\mathrm{x}^{8} \ldots$

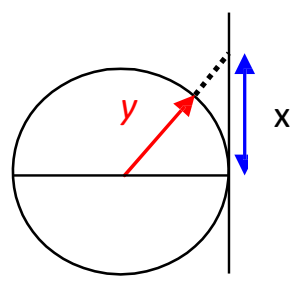

a $x$ correspóndelle $y$

tal que $\tan y=x$

\section{A derivada}

Ao compoñer unha función coa súa inversa obtemos a identidade, de derivada 1.

Neste caso:

$$
x \stackrel{\arctan x}{\longrightarrow} y \stackrel{\tan y}{\longrightarrow} x
$$

Recordarémoslles que a derivada da función composta $g \circ f$ obtense como produto das derivadas, da forma:

$$
(g \circ f)^{\prime}(x)=g^{\prime}[f(x)] f^{\prime}(x)
$$

Coidando de non meter 0 s no denominador:

$$
(g \circ f)^{\prime}(x)=g^{\prime}(y) f^{\prime}(x)=\left(1 / \cos ^{2} y\right) f^{\prime}(x)=1 \Rightarrow f^{\prime}(x)=\cos ^{2} y
$$

De $\tan y=\sin y / \cos y \Rightarrow \tan ^{2} y=\sin ^{2} y / \cos ^{2} y=\left(1-\cos ^{2} y\right) / \cos ^{2} y=\left(1 / \cos ^{2} y\right)-1$

$\Rightarrow 1 / \cos ^{2} \mathrm{y}=1+\tan ^{2} \mathrm{y}$

Obtemos a coñecida relación: $\cos ^{2} y=1 /\left(1+\tan ^{2} y\right)$ e sendo $\tan y=x, \quad f^{\prime}(x)=1 /(1+x 2)$

$\underline{0 \text { erro }}$

0 termo enésimo (termo xeral) desta serie será: $a_{\mathrm{n}}=a_{1} r^{\mathrm{n}-1}=1\left(-x^{2}\right)^{n-1}=(-1)^{n-1} \mathrm{x}^{2 n-2}$

Suma dos $n$ primeiros termos:

$$
S_{n}=\frac{a_{1-} a_{n} \cdot r}{1-r}=\frac{1-(-1)^{n-1} \cdot x^{2 n-2}\left(-x^{2}\right)}{1-\left(-x^{2}\right)}=\frac{1-(-1)^{n} \cdot x^{2 n}}{1+x^{2}}
$$

Se $|x|<1$ podemos calcular a suma dos infinitos termos como un límite ${ }^{4}$ pois, sendo a razón $-x^{2}$, tamén menor ca 1: $\quad \mathrm{S}_{\infty}=a_{1} /(1-\mathrm{r})=1\left(1+x^{2}\right) \quad$ (ii)

A diferenza:

$$
\text { (ii) }-(i)=\frac{(-1)^{n} \cdot x^{2 n}}{1+x^{2}}
$$

Dános o que falta para chegar a $1 /\left(1+x^{2}\right)$ se empregamos $n$ termos, ou sexa, dános o erro que cometemos con $n$ sumandos cando queremos obter a suma dos infinitos termos. Desta maneira:

$$
1 /\left(1+x^{2}\right)=1-x^{2}+x^{4} \ldots+(-1)^{n-1} x^{2 n-2}+\left[(-1)^{n} x^{2 n}\right] /\left(1+x^{2}\right)
$$

\footnotetext{
${ }^{3}$ Porén, non é unha das máis eficientes para obter boas aproximacións a $\pi$, xa que se achega moi lentamente.

${ }^{4}$ Un número menor ca 1 ao multiplícalo por si propio decrece: $x^{2 n} \rightarrow 0$
} 
queda expresado como suma de dúas partes: unha polinómica, fácil de estudar, e outra racional (o erro), máis complicada.

\section{A integral}

Ao realizar, sobre a expresión (iii) a integral definida entre 0 e 1:

$$
\int_{0}^{1} \frac{1}{1+x^{2}} d x=\int_{0}^{1}\left[1-x^{2}+x^{4} \ldots+(-1)^{n-1} \cdot x^{2 n-2}\right] d x+\int_{0}^{1} \frac{(-1)^{n} \cdot x^{2 n}}{1+x^{2}} d x
$$

Recordemos que:

i) Para calquera expoñente $r \neq-1$ :

$$
\pm \int x^{r} d x= \pm \frac{x^{r+1}}{r+1}+\text { cte }
$$

ii)

$$
\int_{0}^{1} x^{r} d x=\left(\frac{x^{r+1}}{r+1}\right)_{0}^{1}=\frac{1^{r+1}}{r+1}-\frac{0^{r+1}}{r+1}=\frac{1}{r+1}, r \neq-1
$$

iii) No Sistema Internacional utilízase o radián: arco cuxa lonxitude coincide co radio; equivale a uns $57^{\prime} 3^{\circ}$.

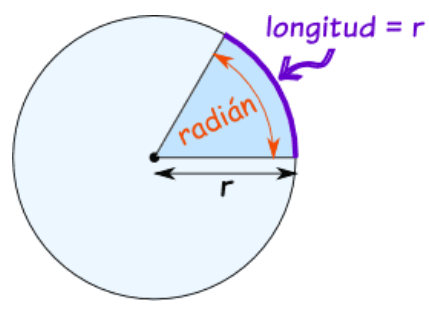

iv)

$$
\int_{0}^{1} \frac{1}{1+x^{2}} d x=[\arctan x]_{0}^{1}=\arctan 1-\arctan 0=\pi / 4-0=\pi / 4
$$

Así chegamos a:

$$
\frac{\pi}{4}=1-\frac{1}{3}+\frac{1}{5}-\cdots+\frac{(-1)^{n-1}}{2 n-1}+(-1)^{n} \int_{0}^{1} \frac{x^{2 n}}{1+x^{2}} d x
$$

e o valor absoluto deste último sumando (o erro que cometeríamos se só utilizásemos $n$ termos) podemos acoutalo ${ }^{5}$ por unha función maior:

$$
\int_{0}^{1} \frac{x^{2 n}}{1+x^{2}} d x \leq \int_{0}^{1} x^{2 n} d x=\frac{1}{2 n+1} \stackrel{n \rightarrow \infty}{\longrightarrow} 0
$$

Concluíndo: $1-1 / 3+1 / 5-1 / 7+1 / 9 \ldots \rightarrow \pi / 4$. Multiplicando por 4 teremos as aproximacións a $\pi$.

A acoutación do erro é un procedemento importante na Ciencia, xa que se o coñecésemos saberíamos o valor exacto (aproximación + erro). 0 interese reside en, non podendo coñecelo,

\footnotetext{
${ }^{5}$ Unha función maior ou igual a outra, ambas as dúas integrables nun intervalo, ten maior integral. $x^{2 \mathrm{n}}$ é máis grande ca $x^{2 \mathrm{n}} /\left(1+x^{2}\right)$, xa que esta última está dividida entre "un e pico". Por certo, é un exercicio interesante de derivadas probar que esta última é crecente no intervalo $[0,1] \operatorname{con} f(0)=0$, para todo $n$.
} 
sermos quen de avalialo. Así, de $\left(^{*}\right)$ sabemos que, en valor absoluto, cando utilizamos $\mathrm{n}$ termos o erro é inferior a $1 /(2 n-1)$, aínda menor ca $1 / 2 n$, se preferimos unha expresión máis sinxela. 